K. Raczynska

J.S. Keller

J. Bujko

S. Halilu Bawa

\section{Energy metabolism in men as influenced by endurance training}

\section{Energieumsatz und Ausdauertraining}

\section{Aim}

The purpose of this study was to investigate whether endurance training has an influence on the magnitude of resting metabolic rate and thermic effect of the meal.

\section{Materials and methods}

Five young endurance-trained male oarsmen (2-3 h/d, $6 \mathrm{~d} / \mathrm{week}$ ) and 5 controls all with an average body weight of $73.2 \mathrm{~kg}$ and ranging in age from $19-24$ years participated in this study. Participants were given a liquid carbohydrate mixture (778 kJ per portion) enriched with vitamins and minerals.
The study was conducted in an open-circuit respiratory chamber with the use of ventilated hood. $\mathrm{O}_{2}$ consumption and $\mathrm{CO}_{2}$ production were analyzed on OXYGOR 6N and UNOR 6N (Maihak, Germany), respectively. The men cycled on a bicycle-ergometer with an effort of $50 \mathrm{~W}$ for 15 minutes.

\section{Conclusions}

Result obtained in this study indicated that

1. Systematic endurance training elevated resting metabolic rate by about $16 \%$ in young adult oarsmen.

2. Endurance training did not have an influence on dietaryinduced thermogenesis in young adult men.

3. Endurance training did not have any impact on the energy cost of physical activity in participants.

4. Resting metabolic rate, dietary-induced thermogenesis and energy cost of physical activity were additive components of energy metabolism in young adult sports men who were the subjects in this study. 